\title{
Super Eyes and Hands for Future Fetal Intervention
}

\author{
Hiromasa Yamashita, Takashi Kakimoto, Wenji Yuan and Toshio Chiba \\ National Center for Child Health and Development \\ Japan
}

\section{Introduction}

With development of prenatal imaging technology diagnosis of fetal and placental disorders are becoming widely accepted in the field of perinatology especially so when some fetal condition may deteriorates before delivery. Awareness of prenatal conditions that may deteriorate before delivery or worsens soon after delivery is invaluable in planning longterm postnatal medical care. The idea of treating a fetus as a patient should never be considered strange or unusual any longer. If the affected fetuses do not undergo any treatment prenatally, devastating complications and/or deaths are likely to ensue.

Fetal surgical procedures are categorized into three categories of ; open surgery (with hysterotomy), endoscopic surgery (without hysterotomy), and ultrasound surgery. Using these procedures, prevention of fetal or neonatal mortality has been increasingly achieved promoting the chances of successful postnatal treatment with improved long-term quality of life. Endoscopic surgery is expected to correct fetal abnormalities using relatively simple modalities. An example of a simple and effective endoscopic surgery is the use of fetal tracheal occlusion to prevent intrauterine progression of pulmonary hypoplasia in congenital diaphragmatic hernia $(\mathrm{CDH})$. As fetuses do not breathe in utero, this treatment's usefulness and importance cannot be overstated. Unlike this procedure, ex utero intrapartum treatment (EXIT), fetal myelomeningocele (MMC) repair, fetal lobectomy for congenital cystic adenomatoid malformation (CCAM), and fetal resection of sacrococcygeal teratoma (SCT) have been based on open procedure. The goal of these procedures is a longterm improvement of postnatal quality of life in case of $\mathrm{MMC}$, and to save the fetal life in case of CCAM or SCT.

Fetal surgery is typically performed on fetuses around 19 to 28 weeks of gestation. The purpose is to treat fetal and placental morphologic defects, which could be diagnosed early before birth, and inhibit their progressions to point of sever fetal compromise. However, it may be complicated by surgical infections, premature labor, premature birth and membrane ruptureThe recent introduction of endoscopic and ultrasound image-guided surgeries have enabled minimally invasive intrauterine surgery (Harrison et al., 2001) thus reducing these potential complications of open fetal surgery to the barest minimum.

Our major target diseases are fetal $\mathrm{CDH}$, fetal $\mathrm{MMC}$, twin-to-twin transfusion syndrome (TTTS) and hypoplastic left heart syndrome (HLHS) or HLHS with restrictive atrial septum 
that inevitablly leads to irreversible pulmonary vascular damages. MMC is a dorsal neural tube defect with highest risk of hydrocephalus as well as motor/perception and vesicorectal disabilities. Although current fetal repair of MMC is to surgically cover and protect the lesion in utero, this procedure is hard to accomplish endoscopically with the use of conventional surgical devices alone (Bruner et al., 1999; Kohl et al., 2006), as a result of a cramped working. TTTS occurs in $10-15 \%$ of monochorionic twin gestations and is caused by placental vascular anastomoses, resulting in an imbalance in blood flow and volume between both twins. In severely affected cases, this syndrome is likely to be associated with high perinatal mortality or postnatal life-long handicaps (Feldstein et al., 2000). As a definitive prenatal treatment, fetoscopic laser photocoagulation of the anastomotic vessels has been widely accepted (Senat et al., 2004; Quintero et al., 2000). Current procedures for correction of restrictive fetal atrial septum are still invasive because they require ultrasoundguided puncture of tiny beating fetal heart (Kohl et al., 2000; Marshall et al., 2004; Mäkikallio et al., 2006).

In order to overcome the challenges of fetal endosciopic surgery, improve surgical outcome and allow for more advanced surgery, we developed sets of new devices that will act as super eyes, super hand and improve navigation. We called them "super eyes", "super hands" and "super navigations".

In this chapter, we present details of these super devices and their applications for future fetal intervention. These technologies is sure to be employed both for stand-alone and combined use.

\section{Super eyes}

An ideal super eyes for intrauterine surgery should be able to exapand the views of the conventional endoscopic and ultrasound machine for preoperative diagnosis, intraoperative activities and visualisation of the operative field as well as postoperative monitoring Achieving this requires the use of high performance endoscopes and high-resolution 3D/4D ultrasound machine. We developed new endoscopes and ultrasound machines that perform the function of super eyes.

\subsection{Three-dimensional fetoscope}

Inside the uterus, fetal bodies and placental tissues are fragile and delicate. The Surgeon must be careful about manipulating surgical instruments, however conventional fetoscopes give only a two-dimensional (2D) view without depth perception. To solve this issue, we developed a miniature three-dimensional (3D) fetoscope of 5.4-mm diameter mounting double 1/10-inch CCDs and lens-units on the distal-end tip including a laser fiber channel of 1-mm diameter for safe laser photocoaguration (Fig. 1) (Kobayashi et al., 2009). This fetoscope can supply surgeons with a 3D front or a diagonally front view without any eye fatigue, enabling safe procedures in the uterus.

\subsection{Fluorescence endoscope}

In TTTS therapy, surgeons must assess anastomotic communicating blood vessels. However, small vessels are often missed due to the poor view which obtained with a fetoscope. 

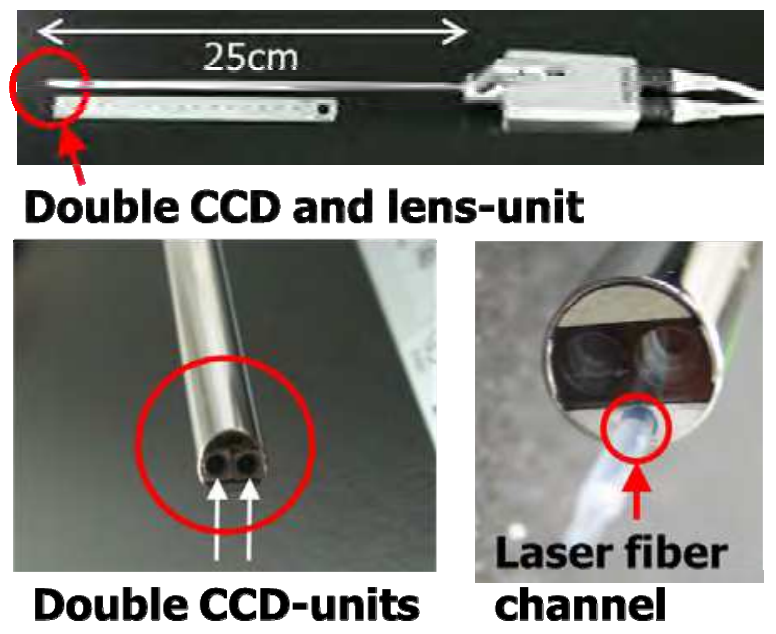

Fig. 1. Appearance of the 3D fetoscope. Miniature double CCD and lens-unit are in the distal-end tip to receive right-eye view and left-eye view. We developed another type of 3D fetoscope with a laser fiber channel.

To help this assessment, we developed a fluorescence endoscope which is capable of visualizing very small vessels, even in the cloudy amniotic fluid (Harada et al., 2009; Ishiyama et al., 2011). We did in vitro test to visualize a placenta of cynomolgus monkey. After the injection of indocyanine green (ICG) into the vessel, the endoscope can detect nearinfrarede fluorescence (peak: $845 \mathrm{~nm}$ ) from the vessels on the placenta in fluorescence mode of the camera. (Fig. 2).

\subsection{Ultra-high sensitive endoscope}

A conventional endoscope needs high-powered light to see inside the uterus. Using this light raises concern about causing negative effect to perinatal fetal ocular development by the intense heat and illumination. Therefore, we developed an ultra-high sensitive endoscope using High-gain Avalanche Rushing amorphous Photoconductor (HARP) camera technology, which has been originally developed by Japan Broadcasting Corporation (Nippon Hoso Kyoukai : NHK) for broadcasting. This endoscope enables observation with extreamely low lighting such as LED (Fig. 3) (Kim et al., 2011). We compared conventional endoscopic image with our new endoscopic image to visualize an intrauterine fetal phantom model without the conventinal light source. (Fig. 4). Our new endoscope enabled to visualize the clear fetal face only with a white LED lighting.

\subsection{High resolution ultrasound}

In current fetus surgery, 3D-ultrasound (3D-US) diagnosis is fundamental to guide endoscopes and surgical instruments. However, the propagation speed of ultrasonic waves are limited so that there is a trade-off between spatial and time resolutions. We developed a high resolution ultrasound apparatus, which includes a new US probe to form transmitting beams simultaneously in two directions and four receiving beams from each transmitting 

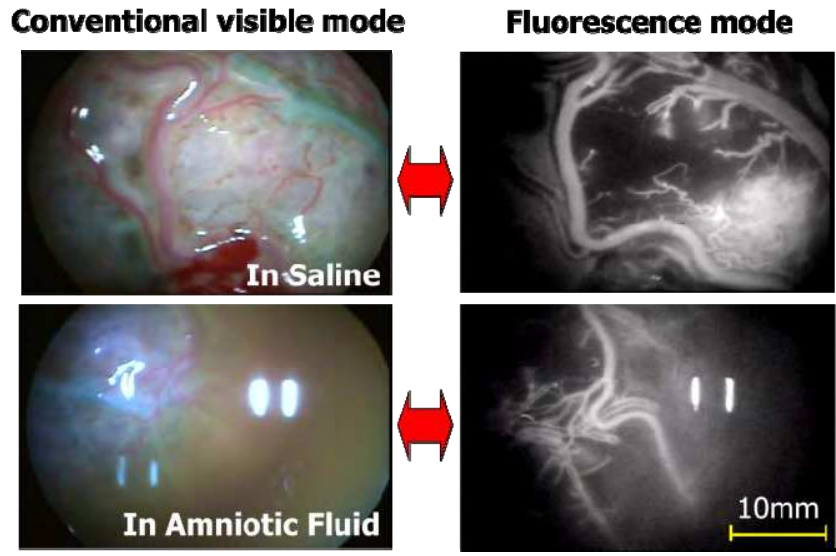

Fig. 2. Fluorescence endoscopic images are visualizing a placenta of cynomolgus monkey. Although the vessels on the placenta are invisible in the cloudy amniotic fluid, they are clearly visible to gain fluorescence from the vessels in the fluorescence mode.

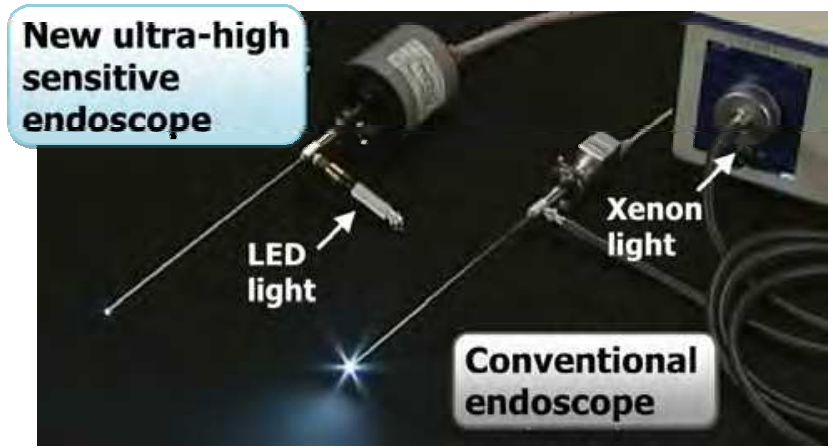

Fig. 3. Appearance of the endoscopes. Left: New ultra-high sensitive endoscope with small LED light. Right: Conventional endoscope with xenon light source.
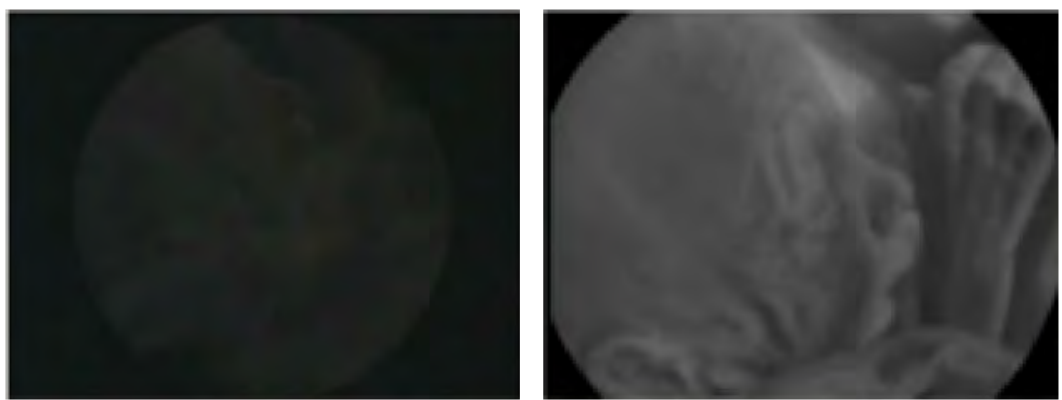

Fig. 4. Comparison of endoscopic image of an intrauterine fetal phantom model without conventional light source. Left: Conventional endoscopic image. Right: New ultra-high sensitive endoscopic image. 
beam, to achieve double density volume data in spatial or time resolution (Fig. 5). Using our new apparatus, moving endoscope near intrauterine fetal phantom model are clearly and smoothly visible without diplopia of the endoscope (Fig. 6).

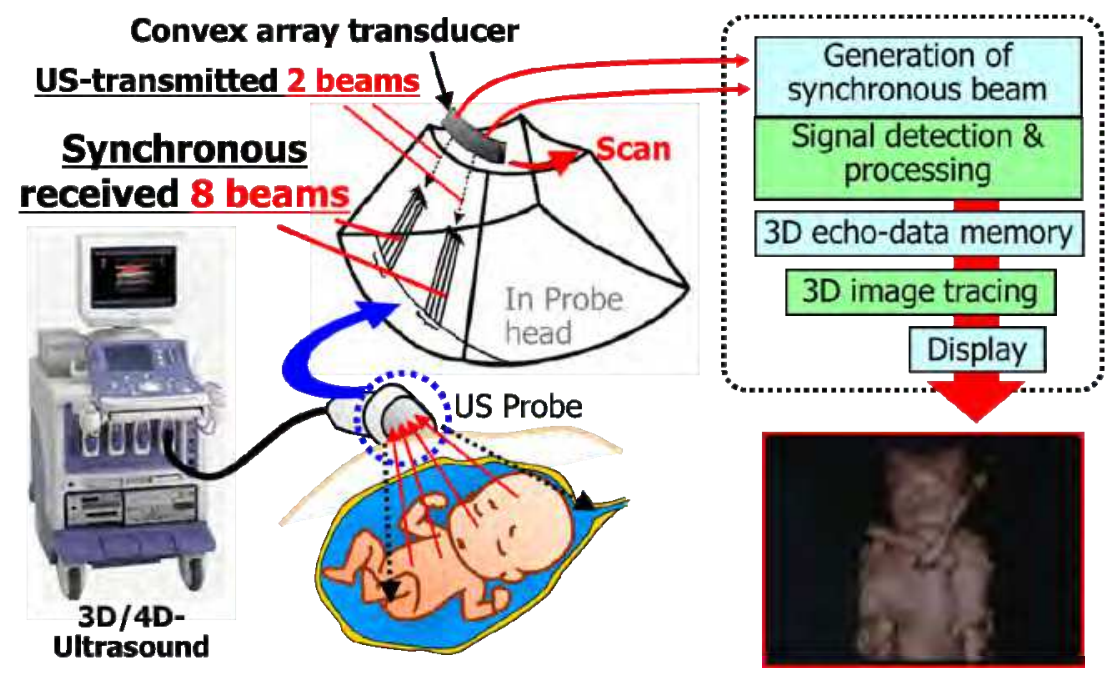

Fig. 5. System configuration of the high resolution ultrasound diagnosis apparatus.

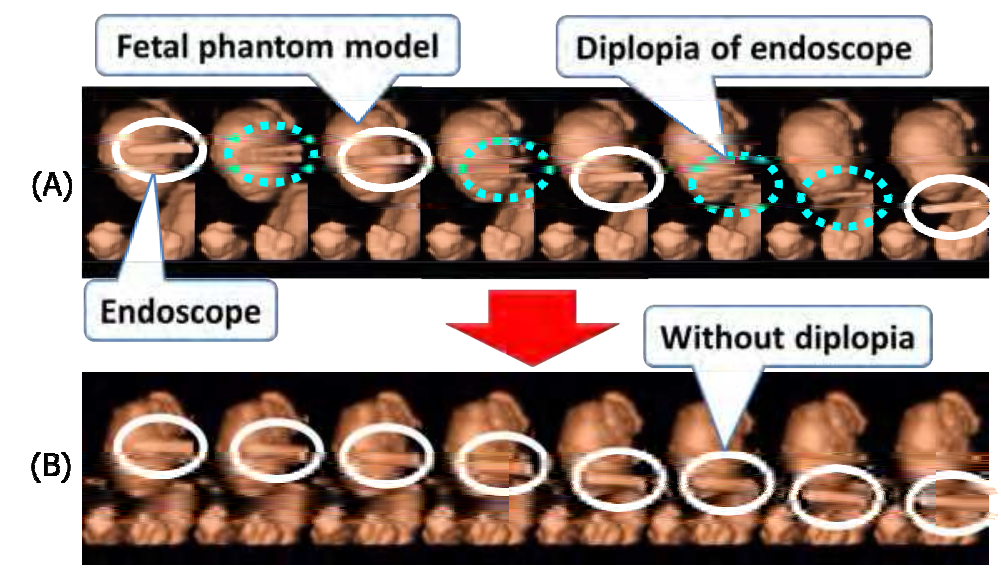

Fig. 6. (A) Conventional 3D-US image including diplopia of the endoscope by frame rate issue. (B) New 3D-US image without diplopia of the endoscope.

\section{Super hands}

To accomplish a safe and dexterous surgical procedure in utero, we developed specified manipulators (multi degrees-of-freedom) as well as fetal stabilizers having multi-joint distal ends. These devices are 4-mm or less in diameter to minimize uterine injuries and/or reduce perioperative complications. 


\subsection{Miniature manipulator}

Manipulation of surgical instruments in the uterus should be safe, careful and dexterous because of fragile tissues of fetal body, placenta, amniotic membrane and so on. For this issue, we developed two miniature bending manipulators which have multi degrees-offreedom (DOFs). One is the wire-guided linkage-driven 3.5-mm manipulator with an easily exchangeable distal end-effector such as forceps and laser fiber (Fig. 7: Left) (Yamashita et al., 2008a). The other is the more miniature wire-driven 2.4-mm manipulator (Fig. 7: Right) (Harada et al., 2006). These manipulators are mainly composed of metal (stainless steel, titanium, etc.) and sterilizable for clinical application.

These manipulators with a laser fiber to photocoagulate placental communicating vessels for laser therapy of TTTS were evaluated by underwater phantom or in vitro experiments (Fig. 8), confirming their performance to photo coagulated a wide range of tissues with flexible bending motions. In addition, the 3.5- $\mathrm{mm}$ manipulator with forceps is controlled manually with one hand to grasp and pass needle or thread in the intrauterine fetal phantom model dexterously by under endoscopic guidance(Fig. 9).
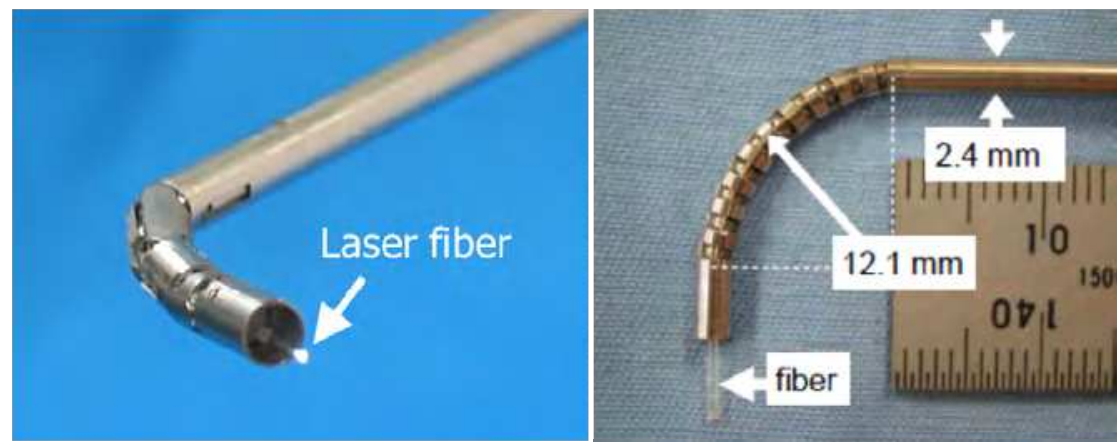

Fig. 7. Distal-end part of the miniature bending laser manipulators with a laser fiber. Left: Wire-guided linkage-driven 3.5-mm manipulator. Right: Wire-driven 2.4-mm manipulator.
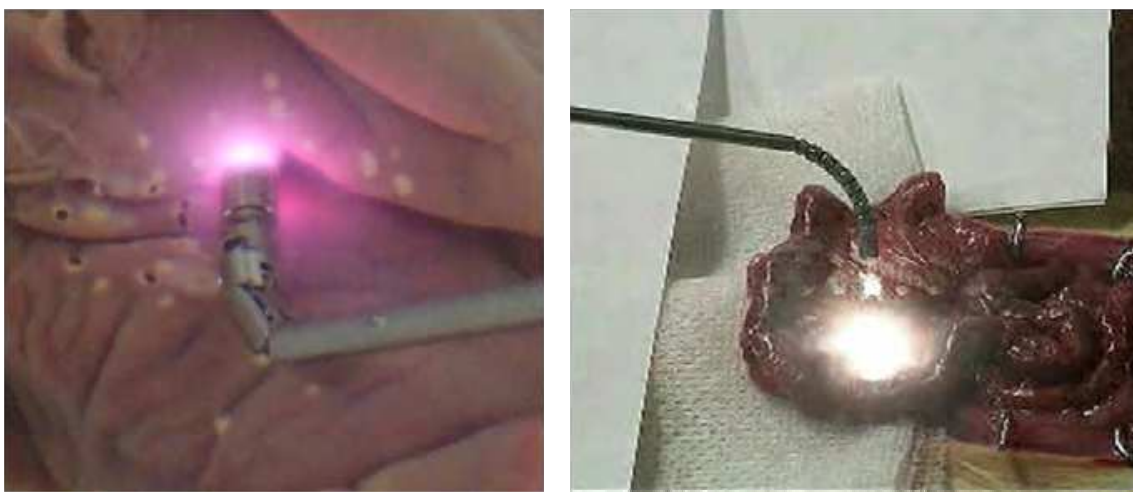

Fig. 8. Left: Nd:YAG laser photocoagulations of the placental phantom model surface with bending motion of the 3.5-mm laser manipulator. Right: Nd:YAG laser photocoagulation of the vessels on the rat mesenterium with the wire-driven 2.4-mm bending laser manipulator. 


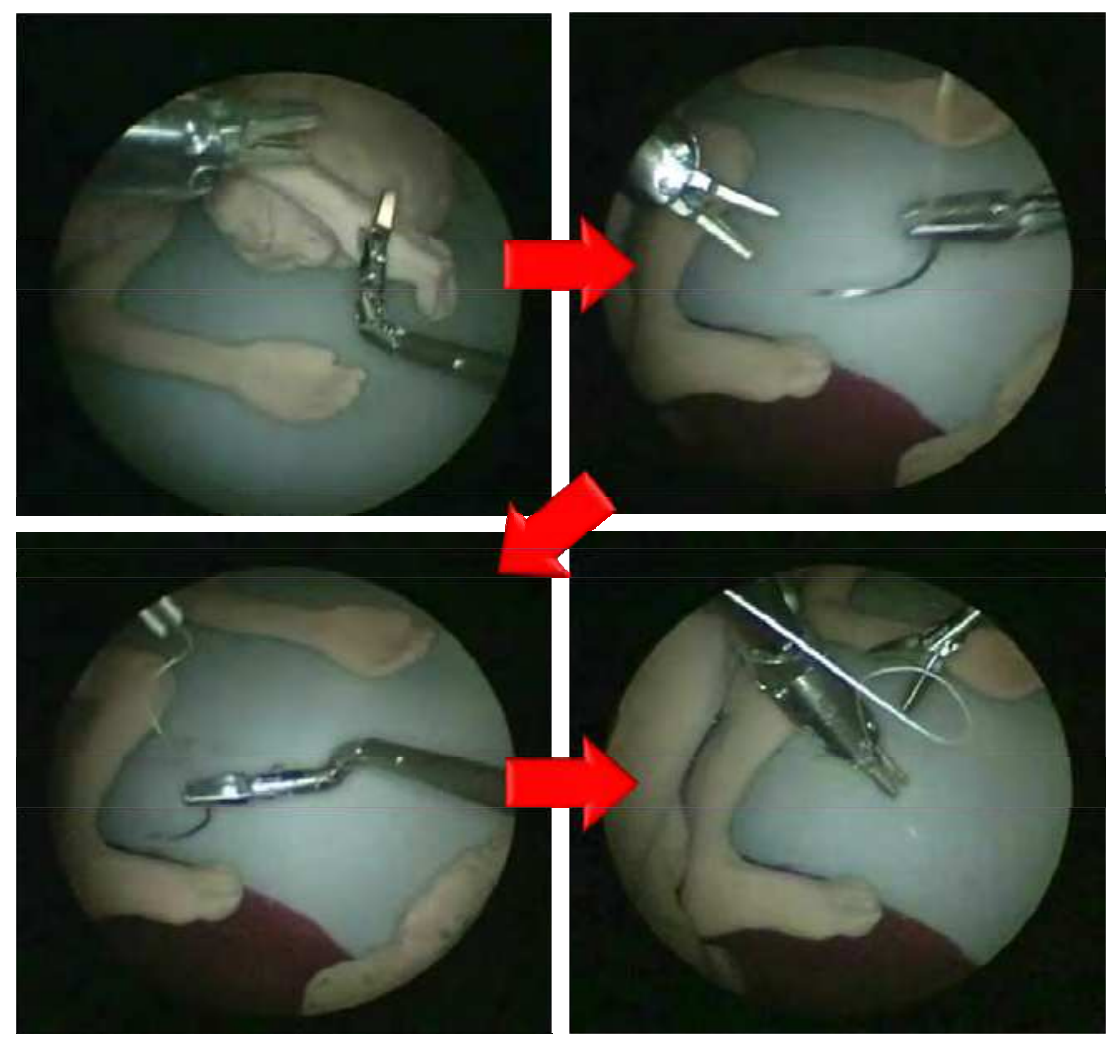

Fig. 9. Bi-manual maneuver evaluation with a new $3.5 \mathrm{~mm}$ forceps manipulator and previously developed 10-mm forceps manipulator. These manipulators performed transferring a needle or thread endoscopically.

\subsection{Bending stabilizer}

Safe approach to the intrauterine fetus is difficult because the fetus is floating and rotating in amniotic fluid. For this issue, we developed two types bending stabilizers, especially for the therapy of MMC with a covering patch and laser therapy of TTTS. One is the 2.4-mm wiredriven bending stabilizer to stabilize around the affected area. And the other is the 4-mm wire and linkage-driven balloon manipulator to hold the fetal whole-body softly (Yamanaka et al., 2008). These devices have multi-joints structure and multi-DOFs to approach fetal body non-invasively. We evaluated these devices and confirmed their effective performance in in vitro test with a cynomolgus monkey's brain tissue (Fig. 10: Upper right) and in phantom test with a silicone model (Fig. 10: Under right). 


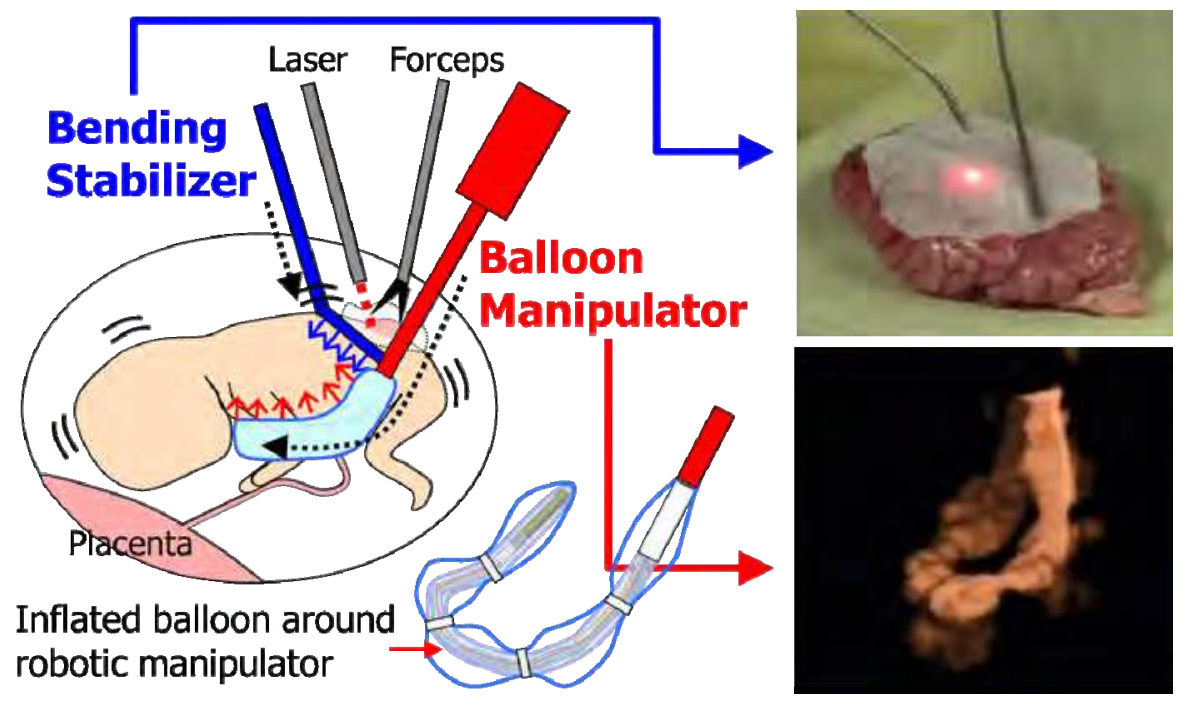

Fig. 10. Bending stabilizer to hold fetal body in uterus. Upper right: In vitro test of the bending stabilizer for laser photocoagulation. Under right: 3D-US image of the bending balloon manipulator in intrauterine phantom model.

\section{Combination of "super eye and hands"}

To ensure synergy and reduce the number of instruments in use during surgey when separate super eyes and hands are used, We developed two types of super device that comprise super eyes and hands to realize real-time capture of fetoscopic images for effective laser photocoagulation in utero: one is the composite-type laser fiberscope and the other is the computer-aided high-intensity focused ultrasound (HIFU) machine.

\subsection{Composite-type laser endoscope}

In current laser therapy in fetal surgery, a glass fiber is aligned parallel with a fetoscope, therefore it is difficult to position the laser spot with adequate distance. To solve this problem, we developed two composite-type laser endoscopes. One is the composite-type laser flexible fiberscope including central mono fiber to pass $40-\mathrm{W} \mathrm{Yb}$ fiber laser to photocoagulate target tissue with focused energy by a distal-end collective-lens (Fig. 11) (Oka et al., 2010). The outer diameter of this fiberscope is $2.2 \mathrm{~mm}$ (Fig. 12), and enables distance measurement with laser Doppler and blood flow detection of targeted blood vessels (Seki et al., 2009, 2010). In in vivo test using pig mesenteric vessel underwater, we confirmed occlusion of the vessels by laser photocoagulation fetoscopically (Fig. 13).

The other is a steerable laser endoscope (Yamanaka et al., 2010). Nd: YAG laser from the laser source is reflected by two galvanomirrors in a galvanometer and a beam-splitter to pass through relay lenses in the rigid endoscope. On the other hand, visible light from the distal end of the endoscope passes through the relay lenses and beam-splitter to CCD camera (Fig. 14). The galvanometer is controlled by indication of the laser spot on the 


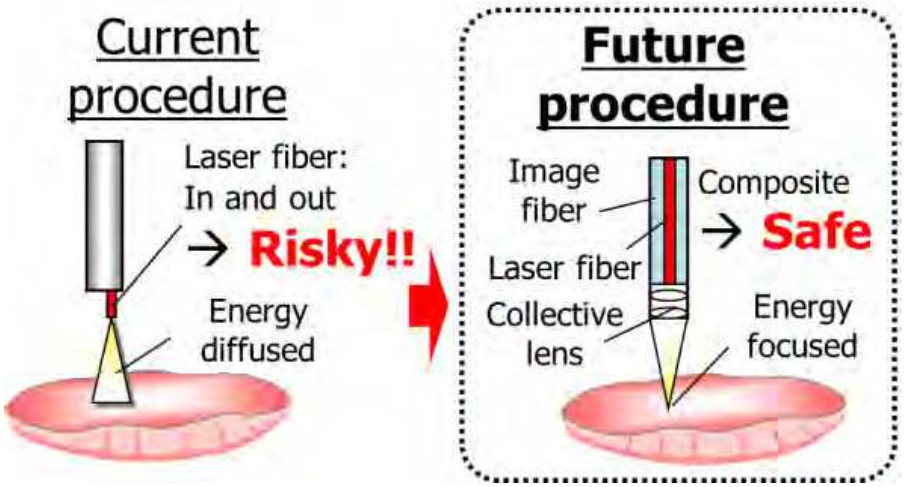

Fig. 11. Concept of the composite-type laser fiberscope.

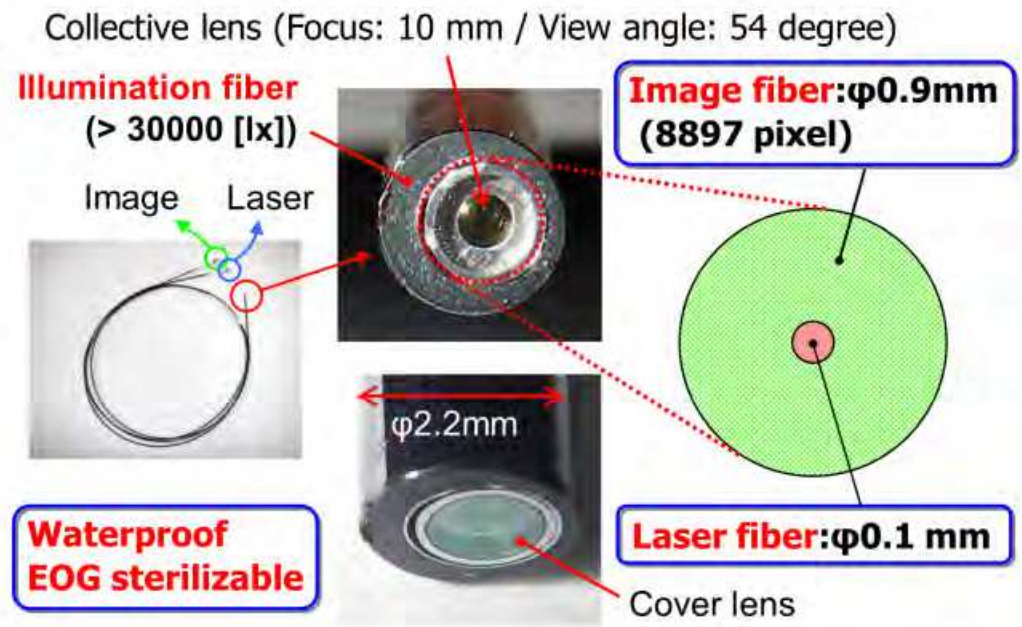

Fig. 12. System configuration of the composite-type laser fiberscope.

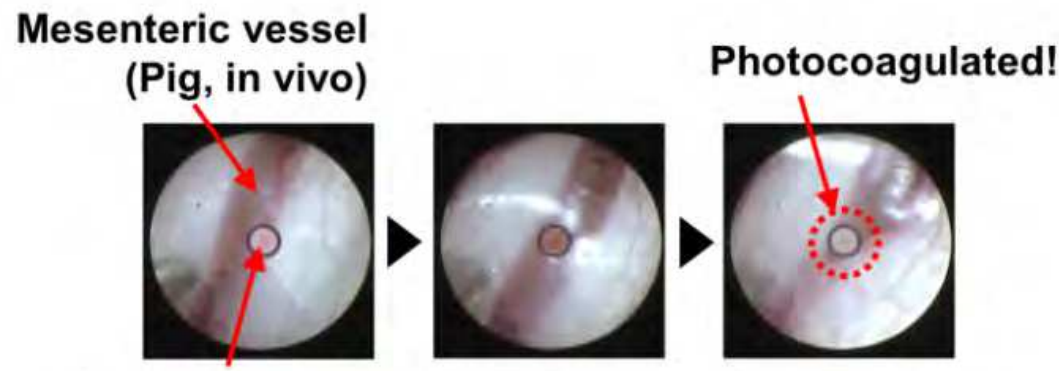

\section{Central laser fiber}

Fig. 13. In vivo test to photocoagulate a mesenteric vessel of swine. 
endoscopic view of PC display to steer direction of the Nd:YAG laser beam (Fig. 15). The positioning of accuracy of the laser spot is mostly within $1.0 \mathrm{~mm}$ in the endoscopic view at the distance between 10 and $20 \mathrm{~mm}$.

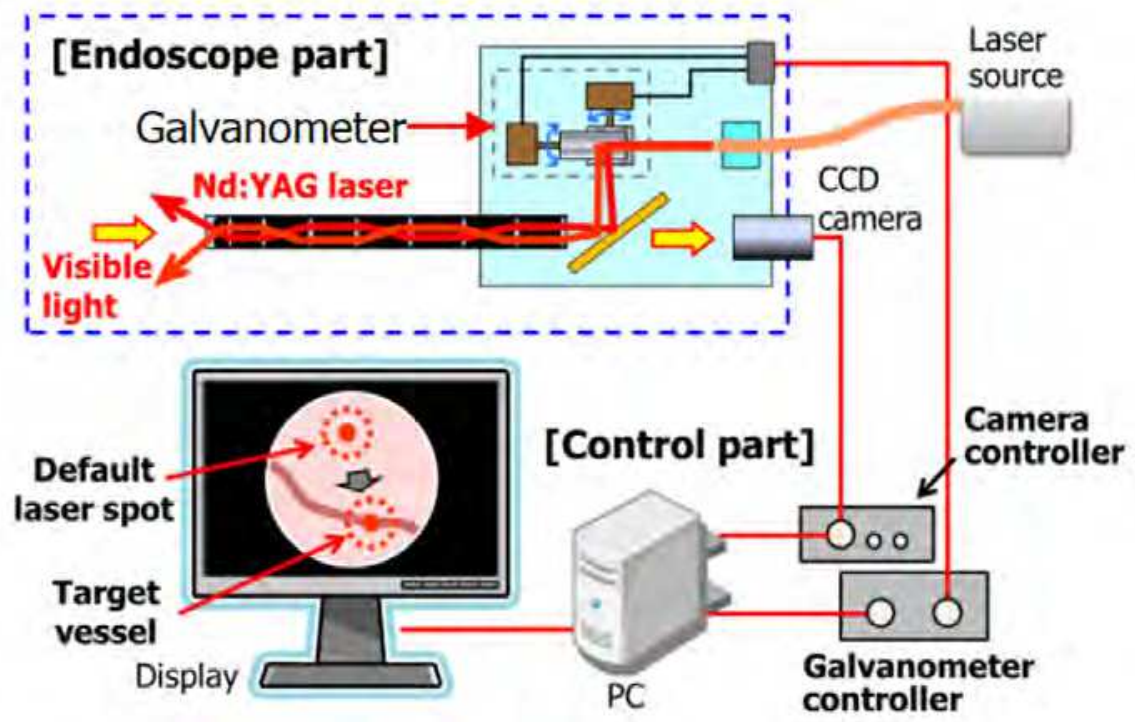

Fig. 14. System configuration of the steerable laser endoscope system.
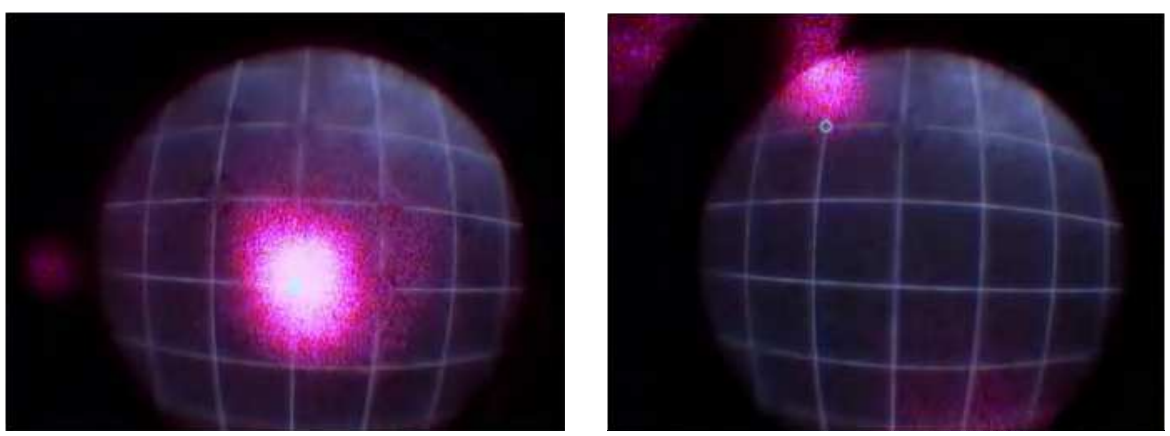

Fig. 15. Laser spot steering control test. Positioning error is around $0.2 \mathrm{~mm}$ in the endoscopic view.

\subsection{Automatic HIFU delivery system}

Current intervention to correct cardiac morphologic abnormalities such as hypoplastic left heart syndrome (HLHS), that is sonographic cardiocentesis for atrioseptostomy is invasive because of penetrating procedure of uterus wall, fetal skin and fetal heart wall. For implementation of minimal invasive cardiac intervention, we take advantage of high intensity focused ultrasound (HIFU), and developed an automatic HIFU delivery system controlled by a real-time computer-based analysis of 2D-US left ventricular images (Fujisaki 


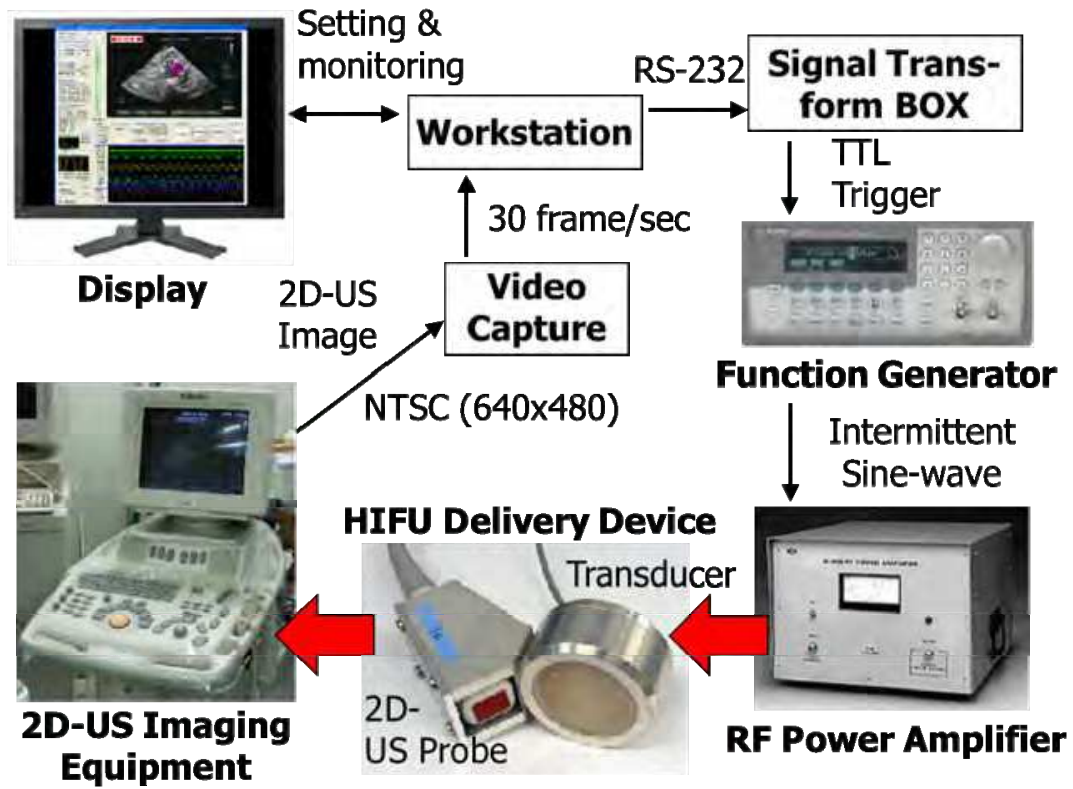

Fig. 16. System configuration of the computer-based automatic HIFU delivery.

et al., 2010; Yamashita et al., 2008b). The system consists of HIFU delivery device with monocoque spherical shaped piezo transducer and diagnostic 2D-US imaging probe, 2D-US imaging equipment, workstation, function generator and RF power amplifier to drive the transducer (Fig. 16). In in vivo evaluation using the beating hearts of anesthetized adult rabbits, the system successfully achieved a non-touch gross ablation and small transmural opening of the atrial septum (Fig. 17).
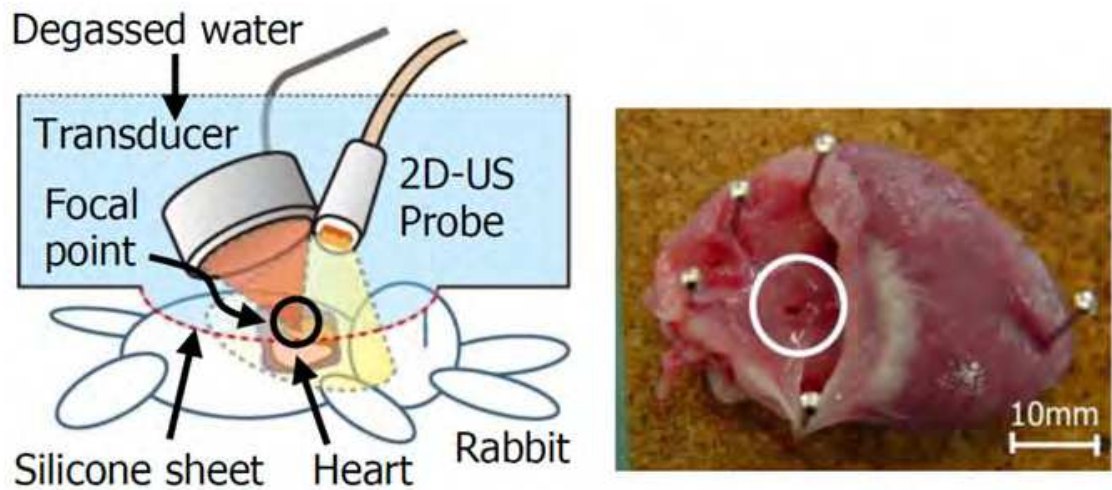

Fig. 17. Experimental setup using an adult rabbit. HIFU delivery was done through a silicone sheet at the bottom of the degassed water tank. 


\section{Super navigations}

To guide surgical devices with much less invasiveness in utero, we developed three navigation systems based on realtime 3D/4D-US data. These systems enable us display of intrauterine operative space for position recognition of devices intuitively.

\subsection{On-site 3D display}

The current 3D-US data is displayed on 2D dusplay such as LCD monitor, however 3Dimage data should be displayed on 3D display from the point of view of intuitiveness. We developed on-site 3D display system using real-time Integral Videography (IV) providing images (or visual display) without any specific glasses unlike general 3D-movie or 3D-TV. Our system can display spatial position and posture of 3D objects precisely by combination of a high-resolution large LCD monitor and a plate of micro-lens array. High-speed computing performs a real-time rendering of 3D-US diagnosis data, and transforms to clear and give a picturesque autostereoscopic 3D-model (Fig. 18). We tested our performance of this system using an intrauterine fetus silicone model, confirming on-site 3D-ultrasaound image of fetus, and surgical instruments from multi-viewpoints with maximum frame rate of $3 \mathrm{~Hz}$ (Fig. 19).

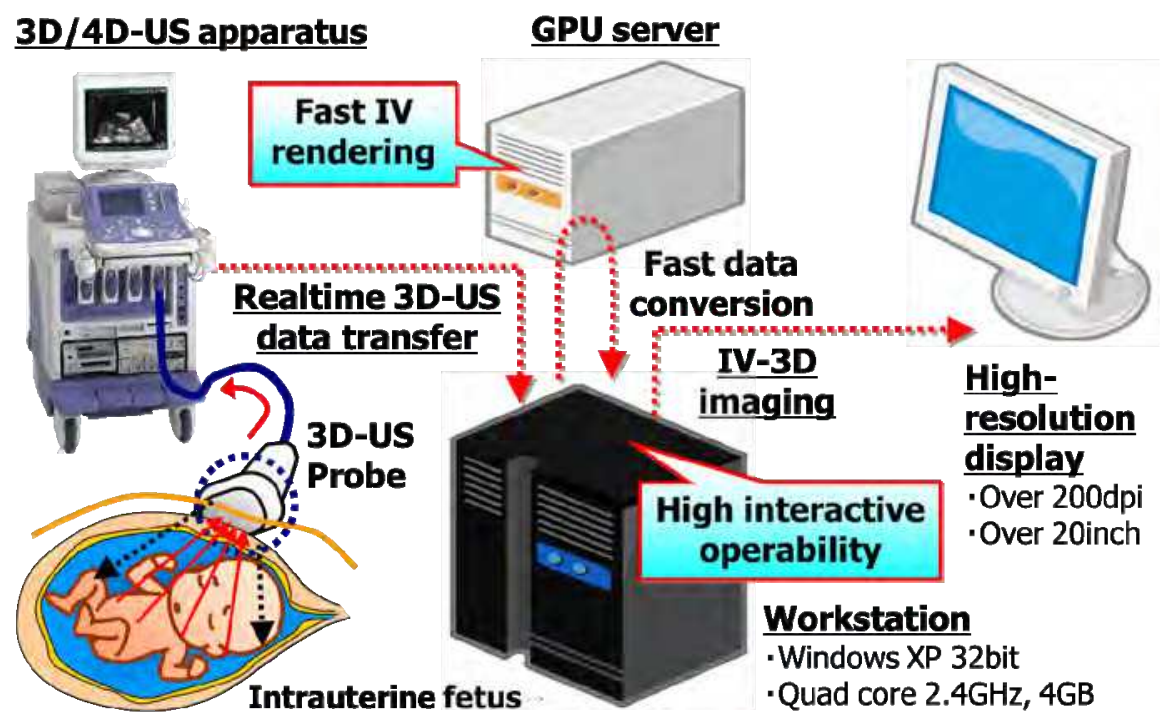

Fig. 18. System configuration of the on-site 3D display with real-time Integral Videography rendering. 


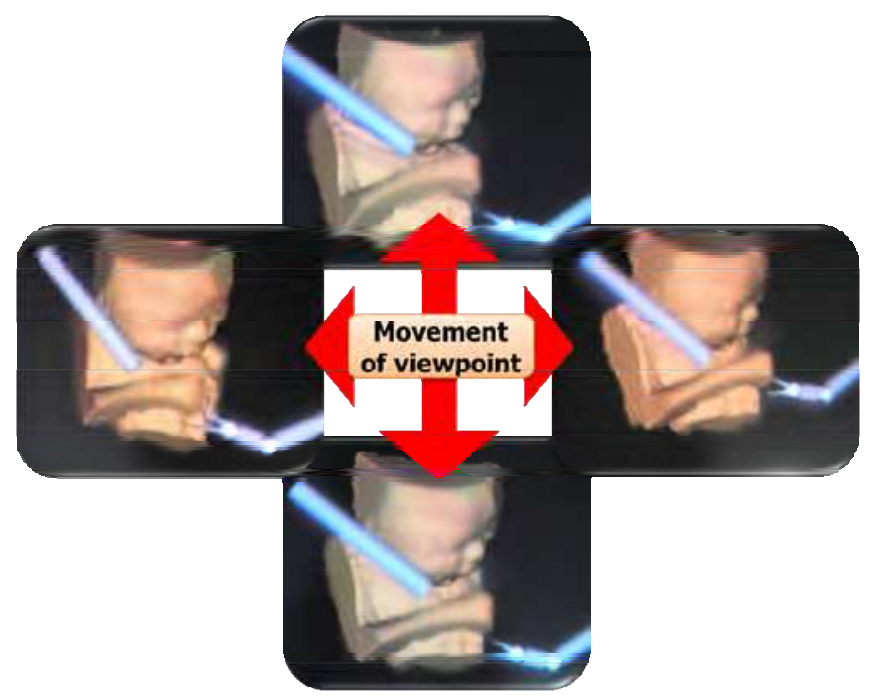

Fig. 19. Feasibility test of the on-site 3D display system to display an intrauterine fetal phantom model with surgical instruments.

\subsection{Distance alarm system}

The interios of the uterus is very narrow and manipulation of instruments requires the utmost attention. To support the manipulation, we developed a distance alarm system based on a real-time updated 3D/4D-US data. After receiving 3D/4D-US data of uterus and high-speed computing with multi-core processor system, the relative positions of intrauterine tissue and surgical tools such as a fetoscope and feoceps are supplied as a color mapping and warning alarm for surgical navigation (Fig. 20). From the result, accuracy of the system was about $3 \mathrm{~mm}$ in position error, and the updating time was about $200-500 \mathrm{~ms}$.

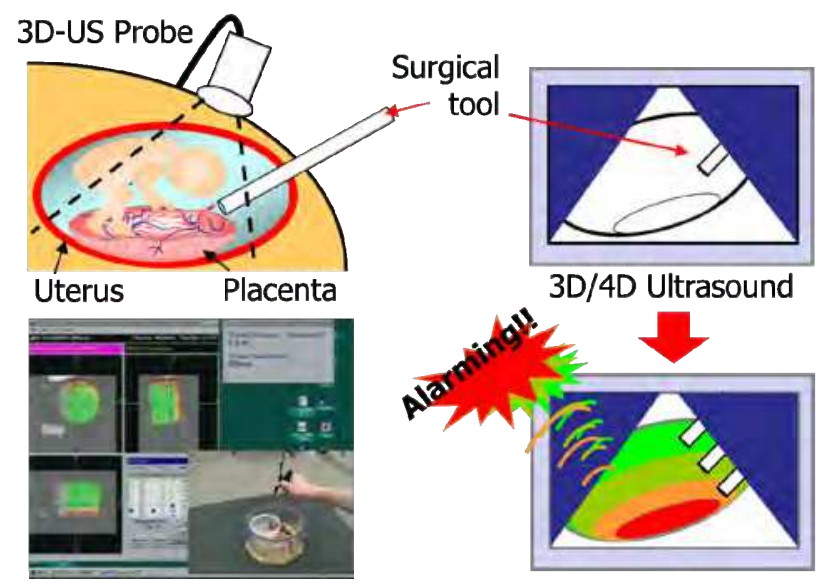

Fig. 20. Color-mapped distance alarming system with alarming caution. 


\subsection{Placental vascular mapping}

In current TTTS laser therapy, the network of placental anastomotic vessels needs to be restructured from the narrow fetoscopic view in the surgeon's head. For this issue, we developed placental vascular mapping system based on the placental 3D-US data and continuous placental vessels' fetoscopic image mosaics (Fig. 21) (Liao et al., 2009). 3D spatial position of the fetoscopic images and the US image are tracked by 3D position tracking device, and the mosaiced fetoscopic images are registered to the surface of 3D-US placenta model by using the fast image rendering method and the seamless multi-images processing. As the fetoscope is moved, the range of placental vessels mapping is enlarged gradually. Results of phantom test show that the system may provide an improved and effrvtive planning and guidance of laser therapy.

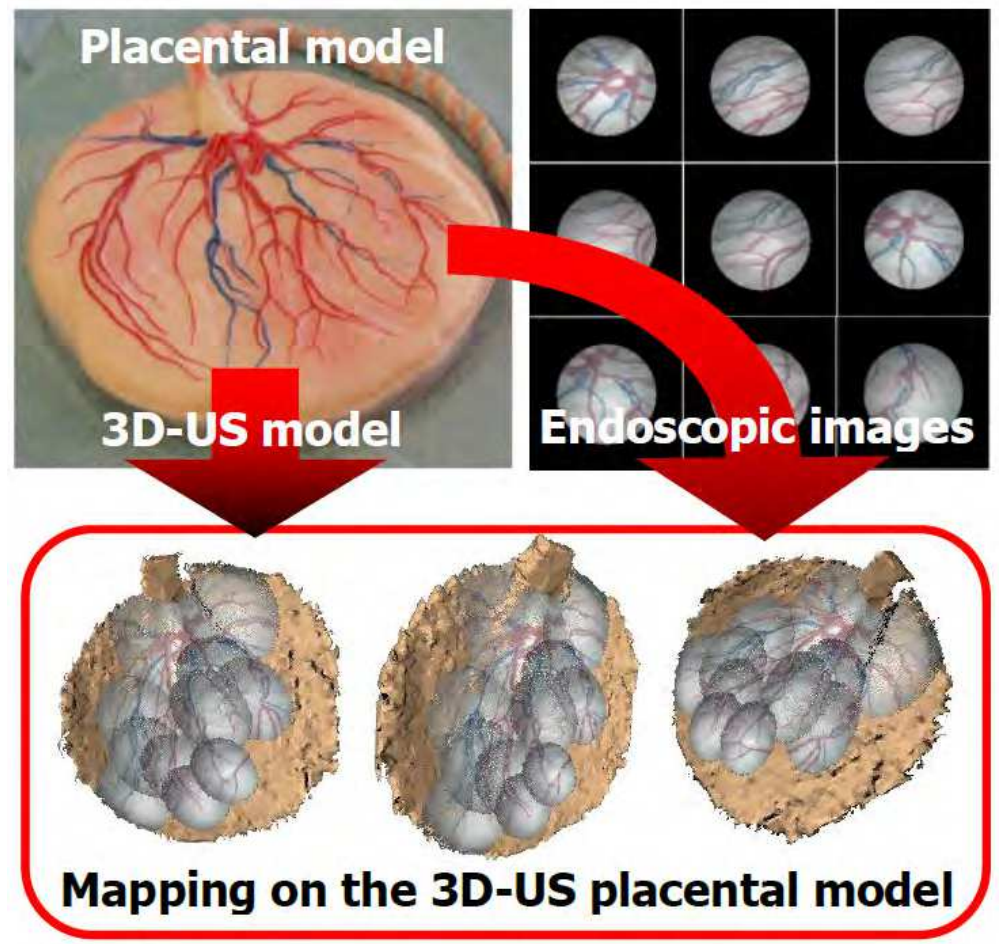

Fig. 21. Placental vascular mapping navigation system to make an entire vessel network by integration of the individual endoscopic images of placenta. 


\section{Conclusion}

Our super devices are certainly useful in future fetal intervention independently. However integration between super eyes, hands and navigations must be more effective surgery, which results in applications in general surgery (Fig. 22). Although part of our device is stil in the experimental phase, there is a device which is ready for a clinical use with high performance. Our research members are making efforts to improve these technologies for future all over the world.

We developed super eyes, hands and navigations of surgeons and these applications for future fetal intervention. These technologies are not only for stand-alone use but also applicable for integrated use. And, because fetal surgery is one of the most difficult surgeries, our achievements will be also applicable to general surgery.

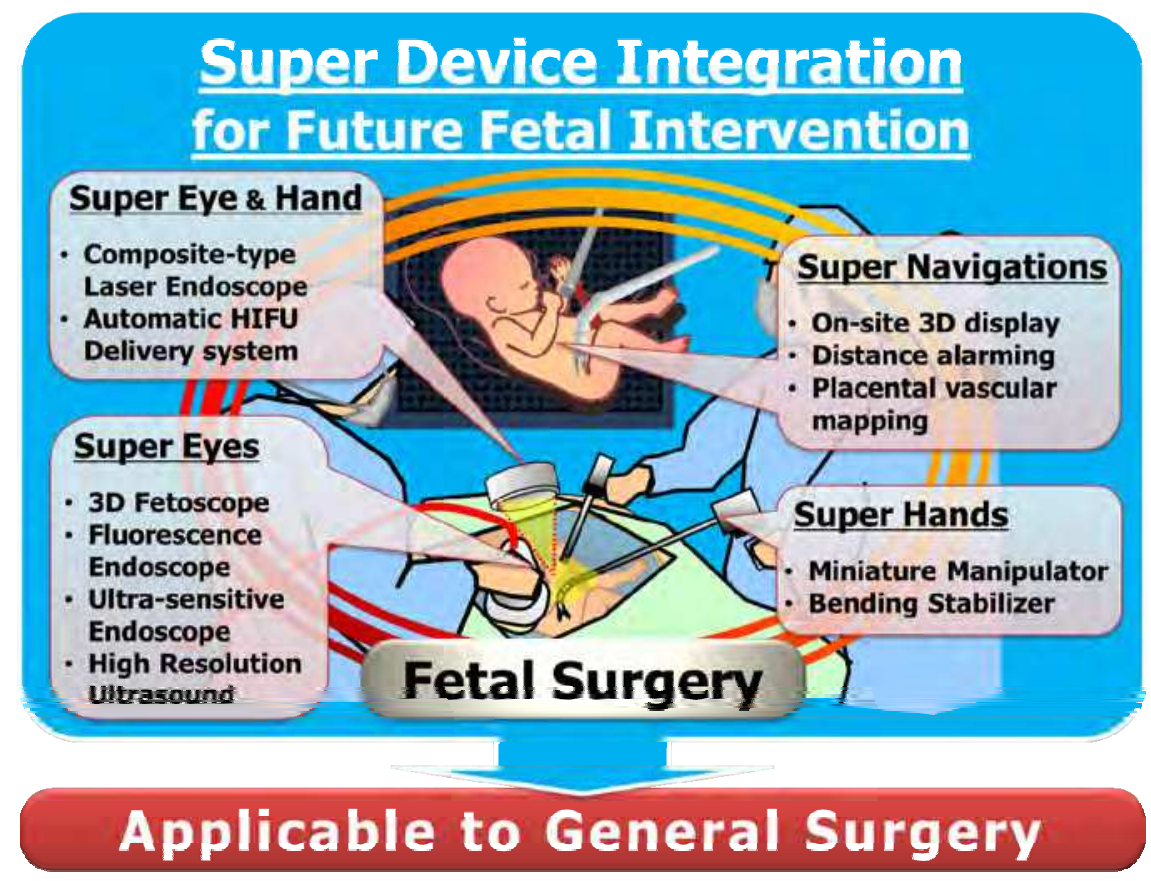

Fig. 22. Overview of super device integration of super eyes, hands and navigations for future fetal intervention, which is applicable to general surgery. 


\section{Acknowledgement}

We wish to thank Akiko Suzuki for help in preparing the manuscript. And a part of this work was supported by Health and Labour Sciences Research Grants (H17-Physi-006, a joint research project among the Ministry of Economy, Trade and Industry, the New Energy and Industrial Technology Development Organization, and the Ministry of Health, Labour, and Welfare (H20-Nano-016), JSPS Grants-in-Aid for Scientific Research (17100008), Research Fellowships of the Japan Society for the Promotion of Science for Young Scientists (041400000227) and Grant Program for Child Health and Development (16-3) administrated by Ministry of Health, Labour and Welfare of Japan.

\section{References}

Bruner, JP., Richards, WO., Tulipan, NB. \& Arney, TL. (1999). Endoscopic coverage of fetal myelomeningocele in utero, American Journal of Obstetrics and Gynecology, Vol. 180, Issue 1, pp. 153-158

Feldstein, VA., Machin, GA., Albanese, CT., Sandberg, P., Farrell, JA., Farmer, DL. \& Harrison, MR.(2000). Twin-Twin Transfusion Syndrome: The 'Select' Procedure. Fetal Diagnosis and Therapy, Vol. 15, No. 5, pp. 257-261

Fujisaki, M., Chiba, T., Enosawa, S., Dohi, T. \& Takamoto, S.(2010). Cardiac intervention using high-intensity focused ultrasound: creation of interatrial communication in beating heart of an anesthetized rabbit, Ultrasound in Obstetrics E Gynecology, 36(5), 607-612

Harada, K., Miwa, M., Fukuyo, T., Watanabe, S., Enosawa, S. \& Chiba, T. (2009). ICG fluorescence endoscope for visualization of the placental vascular network, Minimally Invasive Therapy \& Allied Technologies, Vol. 18, No. 1, pp. 1-5

Harada, K., Iwase, K., Tsubouchi, K., Kishi, K., Nakamura, T., Chiba, T. \& Fujie, MG.(2006). Micro Manipulator and Forceps Navigation for Endoscopic Fetal Surgery, Journal of Robotics and Mechatronics, Vol. 18, No. 3, pp. 257-263

Harrison, MR., Evans MI., Adzick, NS. \& Holzgreve, W. (2001). The unborn patient: the art and science of fetal therapy 3rd edition, Saunders, ISBN 978-0721684468, Philadelphia, USA

Ishiyama, A., Kim, K., Yamashita, H., Miyamoto, Y., Enosawa, S. \& Chiba, T.(2011). New fluorescence endoscope for use in twin-twin transfusion syndrome: In vivo visualization of placental blood vessels. Medical Engineering \& Physics, Vol. 33, pp. 381-385

Kim, K., Kubota, M., Ohkawa, Y., Shiraishi, T., Kawai, T., Kobayashi, A., Yamashita, H. \& Chiba, T.(2011). A novel ultralow-illumination endoscope system, Surgical Endoscopy, Vol. 25, No. 6, pp. 2029-2033

Kobayashi, E., Ando, T., Yamashita , H., Sakuma, I., Fukuyo, T., Ando, K. \& Chiba, T. (2009). A high-resolution, three-dimensional thin endoscope for fetal surgery, Surgical Endoscopy, Vol. 23, No. 11, pp. 2450-2453

Kohl, T., Hering, R., Heep, A., Schaller, C., Meyer, B., Greive, C., Bizjak, G., Buller, T., van de Vondel, P., Gogarten, W., Bartmann, P., Knöpfle, G. \& Gembruch, U. (2006). Percutaneous Fetoscopic Patch Coverage of Spina Bifida Aperta in the Human Early Clinical Experience and Potentioal, Fetal Diagnosis and Therapy, Vol. 21, No. 2, pp. 185-193 
Kohl, T., Sharland, G., Allan, LD., Gembruch, U., Chaoui, R., Lopes, LM., Zielinsky, P., Huhta, J. \& Silverman, NH.(2000). World experience of percutaneous ultrasoundguided balloon valvuloplasty in human fetuses with severe aortic valve obstruction. The American Journal of Cardiology, Vol. 85, Issue 10, pp. 1230-1233

Liao, H., Tsuzuki, M., Mochizuki, T., Kobayashi, E., Chiba, T. \& Sakuma, I.(2009). Fast image mapping of endoscopic image mosaics with three-dimensional ultrasound image for intrauterine fetal surgery, Minimally Invasive Therapy $\mathcal{E}$ Allied Technologies, Vol. 18, No. 3, pp. 32-34

Marshall, AC., van der Velde, ME., Tworetzky, W., Gomez, CA., Wilkins-Haug, L., Benson, CB., Jennings, RW. \& Lock, JE.(2004). Creation of an atrial septal defect in utero for fetuses with hypoplastic left heart syndrome and intact or highly restrictive atrial septum. Circulation, Vol. 110, Issue 3, pp. 253-258

Mäkikallio, K., McElhinney, DB., Levine, JC., Marx, GR., Colan, SD., Marshall, AC., Lock, JE., Marcus, EN. \& Tworetzky, W.(2006). Fetal Aortic valve stenosis and the evolution of hypoplastic left heart syndrome patient selection for fetal intervention, Circulation, Vol. 113, pp. 1401-1405

Oka, K., Seki, T., Naganawa, A., Yamashita, H., Kim, K. \& Chiba, T.(2010). The development of composite-type optical fiberscope system for fetoscopic laser photocoagulation of chorionic plate anastomosing vessels (FLPC), Minimally Invasive Therapy $\mathcal{E}$ Allied Technologies, Vol. 19, No. 2, pp. 94-99

Quintero, RA., Comas, C., Bornick, PW., Allen, MH. \& Kruger, M.(2000). Selective versus non-selective laser photocoagulation of placental vessels in twin-to-twin transfusion syndrome, Ultrasound Obsted Gynecoogyl, Vol. 16, Issue 3, pp. 230-236

Seki, T., Oka, K., Naganawa, A., Yamashita, H., Kim, K., Chiba, T.(2010). Laser distance measurement using a newly developed composite-type optical fiberscope for fetoscopic laser surgery, Optics and Lasers in Engineering, Vol. 48, pp. 974-97

Seki, T., Oka, K., Naganawa, A., Yamashita, H., Kim, K. \& Chiba, T.(2009). Blood flow measurement system for fetoscopic laser photocoagulation of chorionic plate anastomosing vessels, Minimally Invasive Therapy $\mathcal{E}$ Allied Technologies, Vo. 18, No. 6, pp. 350-355

Senat, MV., Deprest, Jan., Boulvain, M., Paupe, A., Winer, N. \& Ville, Y.(2004). Endoscopic Laser Surgery versus Serial Amnioreduction for Severe Twin-to-Twin Transfusion Syndrome. The New England Journal of Medicine, Vol. 351, Issue 2, pp. 136-144

Yamanaka, N., Yamashita, H., Masamune, K., Chiba, T. \& Dohi, T.(2010). An endoscope with 2 DOFs steering of coaxial Nd:YAG laser beam for fetal surgery. Mechatronics, IEEE/ASME Transactions on Mechatoronics, Vol. 15, Issue. 6, pp. 898-905

Yamanaka, N., Yamashita, H., Matsumiya, K., Liao, H., Masamune, K., Chiba, T. \& Dohi, T.(2008). Surgical Manipulator with Balloon for Stabilizing Fetus in Utero under Ultrasound Guidance, Proceedings of Medical Imaging and Augmented Reality 4th International Workshop (MIAR2008), Lecture Notes in Computer Science (LNCS) 5128, pp. 260-269, Tokyo, Japan, July 2008

Yamashita, H., Matsumiya, K., Masamune, K., Liao, H., Chiba, T. \& Dohi, T.(2008a) Miniature bending manipulator for fetoscopic intrauterine laser therapy in twin-totwin transfusion syndrome, Surgical Endoscopy, Vol. 22, No. 2, pp. 430-435 
Yamashita, H., Ishii, T., Ishiyama, A., Nakayama, N., Miyoshi, T., Miyamoto, Y., Kitazumi, G., Katsuike, Y., Okazaki, M., Azuma, T., Fujisaki, M., Takamoto, S., Chiba, T.(2008b). Computer-aided Delivery of High-Intensity Focused Ultrasound (HIFU) for Creation of an Atrial Septal Defect In vivo, Proceedings of Medical Imaging and Augmented Reality 4th International Workshop (MIAR2008), Lecture Notes in Computer Science (LNCS) 5128, pp. 300-310, Tokyo, Japan, July 2008 


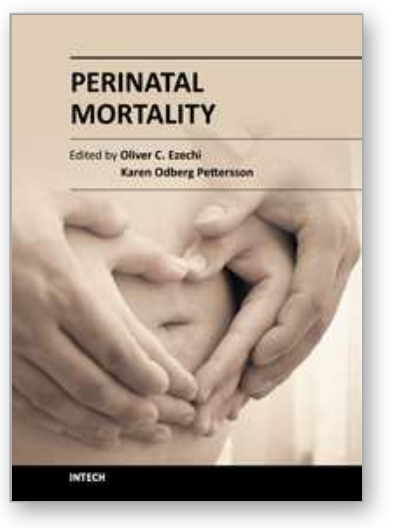

\author{
Perinatal Mortality \\ Edited by Dr. Oliver Ezechi
}

ISBN 978-953-51-0659-3

Hard cover, 148 pages

Publisher InTech

Published online 13, June, 2012

Published in print edition June, 2012

This book is a compendium of important topics related to perinatal mortality. It has been written for anyone who is interested in perinatal medicine and wishes to be part of the global strategy for prevention and control of perinatal mortality. It covers variety of subjects using simple language that can easily be understood by most health workers and those interested in quality health care. Postgraduate students in midwifery, obstetrics and paediatrics will also find it a very useful companion.

\title{
How to reference
}

In order to correctly reference this scholarly work, feel free to copy and paste the following:

Hiromasa Yamashita, Takashi Kakimoto, Wenji Yuan and Toshio Chiba (2012). Super Eyes and Hands for Future Fetal Intervention, Perinatal Mortality, Dr. Oliver Ezechi (Ed.), ISBN: 978-953-51-0659-3, InTech, Available from: http://www.intechopen.com/books/perinatal-mortality/super-eyes-and-hands-for-future-fetalintervention

\section{INTECH}

open science | open minds

\section{InTech Europe}

University Campus STeP Ri

Slavka Krautzeka 83/A

51000 Rijeka, Croatia

Phone: +385 (51) 770447

Fax: +385 (51) 686166

www.intechopen.com

\section{InTech China}

Unit 405, Office Block, Hotel Equatorial Shanghai

No.65, Yan An Road (West), Shanghai, 200040, China 中国上海市延安西路65号上海国际贵都大饭店办公楼405单元

Phone: +86-21-62489820

Fax: +86-21-62489821 
(C) 2012 The Author(s). Licensee IntechOpen. This is an open access article distributed under the terms of the Creative Commons Attribution 3.0 License, which permits unrestricted use, distribution, and reproduction in any medium, provided the original work is properly cited. 